\title{
ARTIGO
}

CO10.22481/praxisedu.v15i33.5289

\section{A ATENÇÃO DOS ALUNOS EM SALA DE AULA: UM ESTUDO COM PROFESSORES DO ENSINO FUNDAMENTAL}

\author{
THE ATTENTION OF STUDENTS IN THE CLASSROOM: A STUDY WITH \\ ELEMENTARY SCHOOL TEACHERS
}

\section{LA ATENCIÓN DE LOS ESTUDIANTES EN EL AULA: UN ESTUDIO CON MAESTROS DE ESCUELA PRIMARIA}

Daniela Karine Ramos

Universidade Federal de Santa Catarina - Brasil

Bruna Santana Anastácio

Universidade Federal de Santa Catarina - Brasil

Camila Meurer Jacob

Universidade Federal de Santa Catarina - Brasil

Mariana Carreira Oliveira

Universidade Federal de Santa Catarina - Brasil

\begin{abstract}
Resumo: A atenção está envolvida em várias atividades cotidianas, como a emissão de respostas, a adequação de comportamentos ao contexto, a regulação de pensamentos e emoções. Diante disso, este artigo tem como objetivo analisar as concepções que os professores possuem sobre a atenção, visando estabelecer comportamentos característicos que podem ser observados em sala de aula e descrever estratégias utilizadas pelos professores para manter a atenção dos alunos. Para tanto, o estudo tem abordagem qualitativa e pauta-se na observação indireta conduzida por meio da realização de entrevistas com 20 professoras do Ensino Fundamental. Os resultados revelam que para as professoras a atenção está mais fortemente relacionada ao foco ou concentração do aluno, seguida pela motivação que inclui o interesse e o envolvimento nas aulas e a participação nas atividades. As estratégias utilizadas para prender a atenção dos alunos incluem o uso de diferentes recursos, conteúdos significativos, destacando-se a proposição de jogos e brincadeiras. Esses aspectos reforçam a importância da atenção para os processos de aprendizagem e como esta habilidade pode estar relacionada a outros fatores.
\end{abstract}

Palavras-chaves: Processo cognitivo. Aprendizagem. Estratégias Didáticas. 
Abstract: Attention is involved in many everyday activities, such as the issuance of responses, the adequacy of behaviors to a context, the regulation of thoughts and emotions. Thus, this article aims to analyze the conceptions that teachers have about attention, aiming to establish characteristic behaviors that can be observed in the classroom and describe strategies used by teachers to keep students' attention. Therefore, the study has a qualitative approach and is based on the indirect observation performed through interviews with 20 primary school teachers. The results reveal that, for teachers, attention is more strongly related to student focus or concentration, followed by motivation that includes interest and involvement in classes and participation in activities. The strategies used to keep students' attention include the use of different resources, meaningful contents, highlighting the proposition of games. These aspects reinforce the importance of attention to the learning processes and how this ability may be related to other factors.

Keywords: Cognitive Process. Learning Process. Didactic Strategies.

Resumen: La atención está involucrada en muchas actividades cotidianas, como la emisión de respuestas, la adecuación de las conductas a un contexto, la regulación de los pensamientos y las emociones. Por lo tanto, este artículo tiene como objetivo analizar las concepciones que tienen los profesores sobre la atención, con el objetivo de establecer comportamientos característicos que puedan observarse en el aula y describir las estrategias utilizadas por los docentes para mantener la atención de los alumnos. Por lo tanto, el estudio tiene un enfoque cualitativo y se basa en la observación indirecta realizada a través de entrevistas con 20 maestros de escuela primaria. Los resultados revelan que, para los docentes, la atención se relaciona más con el enfoque o la concentración del alumno, seguida de la motivación que incluye el interés y la participación en las clases y la participación en las actividades. Las estrategias utilizadas para mantener la atención de los estudiantes incluyen el uso de diferentes recursos, contenidos significativos, destacando la propuesta de juegos. Estos aspectos refuerzan la importancia de la atención a los procesos de aprendizaje y cómo esta capacidad puede estar relacionada con otros factores.

Palabras clave: Proceso cognitivo. Proceso de aprendizaje. Estrategias didácticas.

\section{Introdução}

A atenção está envolvida em várias atividades cotidianas, como a emissão de respostas, a adequação de comportamentos ao contexto, a regulação de pensamentos e emoções. A atenção envolve a concentração da atividade mental (MATLIN, 2003) relacionada a "ativação aumentada, inibida ou a uma combinação de ambas as ações" (STERNBERG, 2008). Essa habilidade relaciona-se a capacidade dos seres humanos de atender seletivamente a certos estímulos do ambiente, ignorando ou inibindo o processamento de outros, menos relevantes (SPENCE, 2012). Isso porque se sabe que o cérebro não possui a capacidade de apreender todos os estímulos perceptivos que recebe constantemente, para tanto, possui na atenção um mecanismo que realiza esta ação, selecionando as informações que são importantes e dispensando outras não relevantes (CONSENZA; GUERRA, 2011; MATLIN, 2003; STERNBERG, 2008). 
Segundo Lezak (1995) a atenção possui quatro classificações, sendo elas a seletiva, que se relaciona a seleção de um foco entre outros existentes; a sustentada, também conhecida como vigilância, onde há a habilidade de permanência da atenção por um período mais longo; a dividida, relacionada à capacidade de se envolver e responder a mais de um elemento/situação em um mesmo momento e atividade, e a alternada, na qual temos que distribuir a atenção para responder a mais de um estímulo num dado momento.

Outro aspecto importante refere-se ao fato de que há duas formas reconhecidas de se regular a atenção, uma vinculada a ativação de modo involuntário da percepção, do pensamento e da ação por meio de estímulos, denominada de atenção reflexa, e a outra realizando estes processos de modo dirigido, proposital e concentrado, conhecida como atenção voluntária (CONSENZA; GUERRA, 2011; BRUNNER; ZELTNER, 1994) Além de aspectos reguladores, a atenção é orientada por três circuitos importantes: o primeiro se relaciona a questões de alerta e vigilância, o segundo proporciona a discriminação sob o estímulo observado, deixando de se atentar a um aspecto para se ater a outro, e o terceiro é o circuito o executivo, o qual inibe os estímulos distratores e possibilita a focalização da atenção até que o propósito seja alcançado (CONSENZA; GUERRA, 2011).

O desenvolvimento da atenção experimenta grandes avanços durante os anos préescolares e, recentemente, evidenciamos algumas tentativas de melhorar a atenção e outras funções executivas por meio de processos de formação (RUEDA; CHECA; CÓMBITA, 2012). Destarte, a atenção está inserida no contexto das funções executivas que possibilitam nossa interação com o mundo a nossa volta, relacionada nas mais diversas situações: organizando nosso pensamento, levando em conta nossos conhecimentos e experiências armazenados na memória, respeitando os valores e propósitos individuais, revelando-se essenciais para garantir o sucesso na escola, no trabalho e na vida cotidiana (CONSENZA, GUERRA, 2011).

Nesse contexto, as funções executivas relacionam-se com habilidades integradas para o controle de que precisamos para nos concentrar e pensar, quando talvez não seja recomendável agir com base em nosso impulso inicial (DIAMOND, 2012). De forma complementar, Consenza e Guerra (2011) entendem as funções executivas como o conjunto de habilidades e capacidades que nos permitem executar as ações necessárias para atingir um objetivo.

Dentre as funções executivas principais, tem-se o controle inibitório que envolve a capacidade de controlar a atenção, o comportamento, os pensamentos e as emoções para substituir uma forte predisposição interna ou atração externa e, em vez disso, fazer o que é 
mais apropriado ou necessário (DIAMOND, 2013). Nesta dimensão destaca-se a atenção seletiva, focada e mantida, priorizando a ação (HARVARD, 2011), pois o controle da atenção nos permite atender seletivamente, focalizando o que escolhemos e suprimindo a atenção para outros estímulos (DIAMOND, 2013).

As funções da atenção relacionadas ao circuito executivo, o qual possibilita que esta se mantenha de modo delongado, no mesmo período que inibe estímulos que promovem a distração, e que está relacionada “[...] aos mecanismos de autorregulação, ou seja, com a capacidade de modular o comportamento de acordo com as demandas cognitivas, emocionais e sociais de uma determinada situação" (CONSENZA; GUERRA, 2011, p. 45), torna a atenção uma das prerrogativas para que a aprendizagem ocorra.

A aprendizagem, sendo um “[...] processo de apropriação e de mudança de comportamento ou de estruturas cognitivas" (BRUNNER; ZELTNER, 1994, p. 19), dispõe de bases para vivências e sobrevivência, sendo parte constituinte e constitutiva do ser humano. A atenção, considerada uma das estruturas biopsicossociais que proporcionam que estímulos sejam captados, analisados, relacionados e transformados em conhecimento, é um dos processos cognitivos imprescindíveis para a elaboração e construção dessas bases e saberes. Assim sendo, com sua capacidade de filtrar estímulos e os focar, com a habilidade de manter regras, controlar impulsos e se apropriar de informações, mudando a atividade mental, a atenção contribui para que a aprendizagem se promova (HARVARD, 2011). Um ponto relevante a salientar neste caminho, é o de que além de condição para a aprendizagem, a atenção pode e deve ser compreendida também como efeito deste processo (NARDIN; SORDI, 2007).

Os processos formativos e atividades intencionalmente organizadas podem melhorar a atenção (RUEDA; CHECA; CÓMBITA, 2012). Atividades como tocar um instrumento ou jogar podem produzir melhorias nos processos de aprendizagem, porque as redes neurais de áreas envolvidas no controle executivo da atenção quando exercitado e fortalecido por meio do treinamento produzem melhorias em outras tarefas executivas, incluindo a inteligência geral (HARDIMAN et al, 2009).

A aprendizagem tem na atenção uma importante função intelectiva, pois é através dos estímulos que recebemos por intermédio dos cinco sentidos, que seleções são realizadas com a finalidade de direcionar o foco a um determinado ponto relevante, enquanto outro é dispensado. Considerando, a atenção um espaço onde ocorre o armazenamento temporário de uma informação (MOURÃO JUNIOR; MELO, 2011) e a aprendizagem o resultado dessas 
assimilações, é possível conjecturar a importância de uma para com a outra (LADEWIG, 2000; RAMOS et al., 2017).

Os direcionamento e redirecionamentos que realizamos com a atenção e, consequentemente, com a aprendizagem, estão relacionados à recepção de estímulos externos e internos, onde estes últimos, vinculados a aspectos de interesse pessoal, estão presentes “[...] quando focalizamos nossos pensamentos, resolvemos problemas ou tomamos decisões conscientes" (CONSENZA; GUERRA, 2011, p. 42).

É neste sentido que as discussões e estudos relacionados ao ensino, tendo como base a singularidade e contexto do sujeito tem conquistado espaço. É por meio da relação de saberes que possuem vinculação com o arquivo de experiência pessoal que a aprendizagem terá seu espaço de construção, pois o cérebro absorve com maior impacto e vivacidade nas vivências e nos saberes significativos e que promovam o bem-estar e as condições de sobrevivência (GUERRA, 2011), permitindo que participem de experiências e que vivam como parte integral da sociedade.

Diante da relevância da atenção para o processo de aprendizagem pesquisas tem sido desenvolvidas relacionada a temática, como de Nardin e Sordi (2007) realizada com crianças de primeira série do ensino fundamental a respeito da atenção em sala de aula e de sua possibilidade de ser concretizada de modo inventivo e problematizador, com base em uma pesquisa qualitativo, com abordagem etnográfica. Os resultados sugerem que a atenção dos alunos é favorecida por um ambiente em que se proporcione uma comunicação dialógica, na qual aspectos e conhecimentos elencados e trazidos pelos alunos são valorizados e utilizados como base para que novas interpretações e ressignificações sejam construídas, possibilitando o enaltecimento do pensamento, o sentimento e postura de pertencimento e acolhimento, a receptividade com a ideia e posição do outro e a "[...] vivência de experiências regidas pelo princípio da cooperação e da reciprocidade.” (NARDIN; SORDI, 2007, p.105).

Outra pesquisa na área, de Micaroli, Crenitte e Ciasca (2010), realizada por meio da aplicação de um questionário de múltipla escolha, investigou as atitudes práticas dos professores de Ensino Fundamental frente à atenção e ao conhecimento dos mesmos sobre esse processo cognitivo. A análise dos dados teve uma abordagem qualitativa e quantitativa e os resultados demonstraram que os profissionais pesquisados possuem a compreensão da diferença existente entre a desatenção e o Transtorno de Déficit de Atenção - TDA , mas possuem dificuldades para identificar situações de desatenção e TDA, bem como em realizar a diferenciação entre distração e dispersão, os quais são importantes elementos que subsidiam uma prática pedagógica adequada. 
Ribeiro (2015) com a finalidade de investigar se a aplicação de jogos cognitivos da Escola do Cérebro trazem desenvolvimento, aprimoramento e potencialização da capacidade de atenção na interação com os jogos dentro do ambiente escolar, realizou um estudo com abordagem qualitativa e quantitativa, com a participação de 30 alunos de 6 a 11 anos do Ensino Fundamental I. Os instrumentos para a coleta de dados utilizados com os professores foram a aplicação de entrevista, de escala de atenção e questionário; com os pais questionário e teste de atenção, e com os alunos, aplicação de testes de avaliação da atenção e de escala de inteligência, e os jogos eletrônicos. A pesquisa trouxe subsídios que indicam que estes últimos colaboram e contribuem na habilidade de manter a atenção, assim como o desenvolvimento de capacidades afins, e que o jogo auxilia no processo de aprendizagem, ao sustentar a atenção e administrar as atividades a serem desenvolvidas para se chegar ao propósito final (RIBEIRO, 2015).

Diante disso, este artigo tem como objetivo analisar as concepções que os professores possuem sobre a atenção, visando estabelecer comportamentos característicos que podem ser observados em sala de aula e descrever estratégias utilizadas pelos professores para manter a atenção dos alunos. Para tanto, o estudo pauta-se na observação indireta realizada por meio da realização de entrevistas com professores do Ensino Fundamental.

\section{Metodologia}

A pesquisa realizada caracteriza-se por se um estudo exploratório de abordagem qualitativa, pautada na observação indireta realizada por meio de entrevistas com professores dos anos iniciais do Ensino Fundamental.

\section{a) Participantes}

Participaram da pesquisa professoras, todas do sexo feminino, com idade média de 36,25 anos (desvio padrão = 9,05) que atuam nos anos iniciais do Ensino Fundamental.

No que se refere ao perfil dos participantes $85 \%(n=17)$ possui formação em licenciatura, sendo $75 \%$ em Pedagogia, duas afirmaram não ter licenciatura porque ainda não concluíram a graduação. 
Tabela 1 - Nível de formação das professoras participantes.

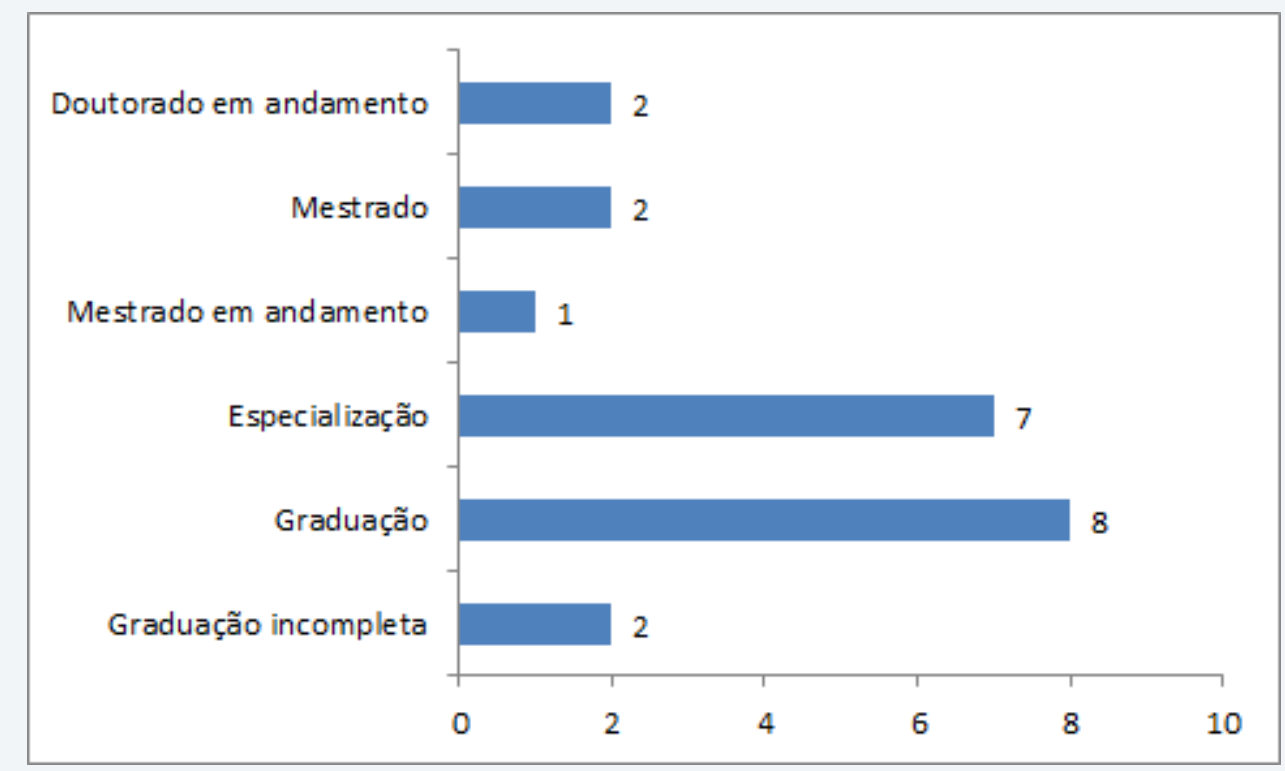

A caracterização do tempo de experiência como professoras revelou que em média as participantes possuem 10,25 anos de experiência. Porém, temos uma variação de 1 a 30 anos, contabilizando um desvio padrão 9,23.

b) Instrumentos e procedimentos metodológicos

A coleta de dados foi realizada por meio de entrevistas feitas individualmente com professores do Ensino Fundamental, como base em um roteiro semiestruturado que incluía questões como: o que entende por atenção? Como sabia se um aluno está ou não atento em sala de aula? O que fazia para tentar manter a atenção dos alunos em sala? E o que mais prendia a atenção do aluno em sala de aula?

Além disso, foram coletadas algumas informações pontuais para caracterização dos participantes, como idade, formação e tempo de experiência como professor.

As transcrições das entrevistas foram feitas em um formulário online para facilitar a organização e a criação da base de dados a ser analisada.

c) Análise dos dados

As entrevistas transcritas foram analisadas por meio da análise de conteúdo proposta por Bardin (2007) como um conjunto de técnicas de análises das comunicações visando obter por procedimentos sistemáticos e objetivos de descrição do conteúdo das mensagens indicadores (quantitativos ou não) que permitam a inferência de conhecimentos relativos às condições de produção/recepção (variáveis inferidas) destas mensagens. Para tanto, observou- 
se três etapas distintas: a formulação das hipóteses e objetivos, incluindo a preparação do material; a exploração do material e o tratamento de resultados, inferência e interpretação (BARDIN, 2007).

O processo de análise foi realizado com o apoio do software NVivo 11, o qual permitiu criar os nós relacionados as categorias e subcategorias de análise, a classificação das partes das transcrições e o registro da frequências das categorias, bem como a construção de nuvens de palavras.

\section{Resultados e Discussão}

Inicialmente, buscou-se identificar e analisar o que os professores entendem por atenção, por meio da descrição de comportamentos característicos de seus alunos em situações que os percebe atentos ou desatentos em sala de aula. Diante disso, retomando a atenção como um mecanismo que permite selecionar as informações que são importantes, dispensando aquelas não relevantes (CONSENZA; GUERRA, 2011, MATLIN, 2003, STERNBERG, 2008). A partir da análise das transcrições das entrevistas com os professores identificamos que a atenção está mais fortemente relacionada ao foco ou concentração do aluno, seguida pela motivação que inclui o interesse e o envolvimento nas aulas e a participação nas atividades.

Tabela 2 - Concepções sobre atenção e frequências registradas.

\begin{tabular}{lc}
\hline Concepção de atenção & Frequência \\
Foco e concentração & $\mathbf{7}$ \\
Motivação & $\mathbf{5}$ \\
Participação do aluno & $\mathbf{3}$ \\
Compreensão do conteúdo & $\mathbf{2}$ \\
Processo Cognitivo & $\mathbf{1}$ \\
\hline
\end{tabular}

Destacam-se na percepção dos professores a atenção associada a foco e concentração como ilustrada na fala: “Atenção pra mim é sinônimo de concentração, significa que você está interessado no que está acontecendo. O aluno volta a sua energia e foco para isso." 
(Entrevistado 4) ou ainda de forma mais geral: "É quando o aluno está concentrado na explicação do conteúdo e faz perguntas” (Entrevistado 3). Através da fala das professoras observamos que para elas é possível perceber se o aluno está concentrado ou não pelo modo como realiza uma atividade, ou seja, quando ele "faz perguntas" (entrevista 3), "olha para a professora" (entrevista 17) ou pela "expressão corporal" (entrevista 7).

Outra palavra frequente na explicação sobre a atenção foi o interesse e envolvimento, relacionados à motivação do aluno, como ilustra a fala da professora 6: "É quando o aluno consegue ter interesse no que o professor está falando, no que está fazendo e propondo, o foco está na proposta. A criança por ser agitada, mas não quer dizer que não tenha atenção se for do interesse dela" ou ainda relacionada ao envolvimento das aulas, como ilustra a fala: "Envolvimento do aluno da atividade” (Entrevistada 19). Diante disso, os professores acreditam que a motivação do aluno durante as aulas contribui para eles fiquem mais atentos à explicação da professora, aos comandos e atividades propostos em sala de aula.

Esses aspectos reforçam que existem relações entre atenção e motivação, expressa principalmente pelos professores entrevistados ao ressaltarem que a atenção aumenta há um indicativo de que o aluno está motivado. Corrobora-se, assim, com a pesquisa realizada em relação ao uso de jogos cognitivos de Ribeiro (2015) que enfatizou uma relação entre atenção e motivação, pois identificou que as crianças que permanecem atentas por períodos cada vez mais longos sentem-se motivados para prosseguir nas tarefas dos jogos.

Nesse sentido, Consenza e Guerra (2011) comentam que somos capazes de modular nosso comportamento de acordo com nossas demandas cognitivas, ou seja, podemos estar mais atentos a determinados estímulos em detrimento a outros, ressaltando que a escolha dos estímulos para darmos nossa atenção está ligada fortemente aos nossos interesses pessoais. De forma complementar Lent (2010) ressalta que a atenção dirige o interesse da pessoa para aquilo que considera importante para atingir seus propósitos

Quanto aos exemplos de situações citados pelos professores que indicam atenção e desatenção durante as aulas, foram destacados como forte comportamento de atenção: a participação e o feedback, acrescentando que no processo de avaliação é possível perceber os efeitos da atenção em sala de aula. 
Gráfico 1 - Comportamentos descritos que indicam atenção dos alunos.

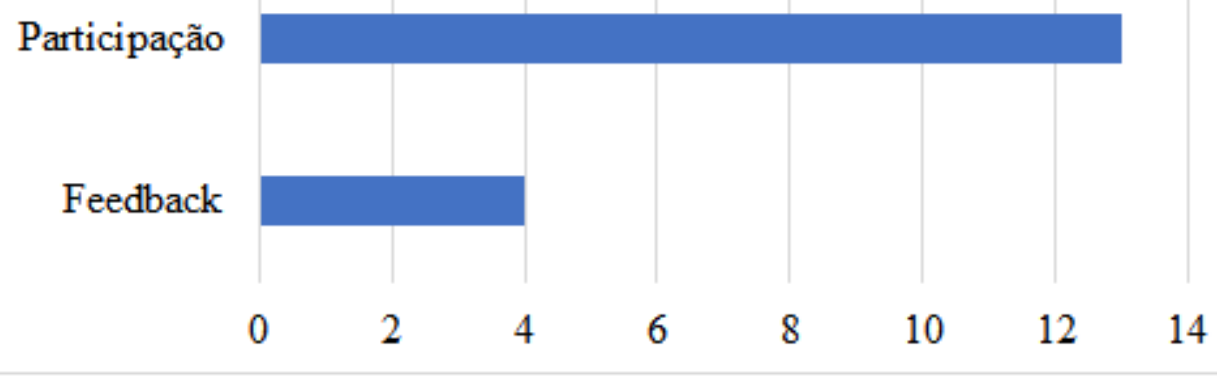

Desse modo, a atenção é percebida pelas atitudes dos alunos relacionadas à participação nas aulas das mais diversas formas como ilustram as falas a seguir: "Quando o aluno faz perguntas, responde às perguntas das professoras, quando pergunta sobre o que tá sendo conversado, tira dúvidas quando não tá conseguindo e pede ajuda; quando participa." (Entrevistada 10) ou ainda "Após uma explicação de determinado conteúdo o aluno faz perguntas, participa ativamente, comenta e faz observações a respeito do conteúdo" (Entrevistado 3). Inserido no contexto da participação a entrevistada 8 percebe que além de fazer perguntas, o aluno atento faz relações com suas vivências e experiências de vida, tornando a aprendizagem mais significativa como ilustra a fala: "A partir de uma observação da criança sobre esse assunto: quando ela cita algum exemplo ou faz relações com suas vivências e experiências; quando responde ou faz indagações com novas questões relacionadas ao tema: quando faz comentário em algum outro momento sobre o tema" (Entrevistada 8). O feedback após as aulas também foi sentido como importante para alguns professores, ressaltados nas falas: "Pedir para eles escreverem ou contarem o que entenderam, uma avaliação no final, se elelela vai falar alguma coisa que tem a ver com o que foi vivido no período" (Entrevistado 1) ou ainda "Depois da aula sobre a explicação, sabe responder as perguntas ou faz perguntas" (Entrevistado 14).

A partir disso, têm-se as relações entre atenção e aprendizagem estabelecidas através do entendimento de aprendizagem como processo e mudança de comportamento (BRUNNER; ZELTNER, 1994). Diante disso, Lima (2009) refere-se à atenção como ingrediente fundamental para a aprendizagem, pois o processo de aprender algum conceito requer a observação, a categorização e a análise, o que envolve a atenção. Dessa forma, Ribeiro (2015) comenta que a aprendizagem vai se efetivando pela criação de novas memórias, pela ampliação e transformação de redes neuronais. 
Além disso, Ladewig (2000) ressalta que a aprendizagem é o resultado de assimilações e que estas dependem da nossa atenção, do foco para estabelecer conexões e associações sobre determinado estímulo.

De outro modo, a desatenção tem como comportamentos indicadores as conversas sobre outros assuntos, as brincadeiras, o uso do celular e não saber responder o que é perguntado ou solicitado.

Gráfico 2 - Comportamentos descritos pelas professoras que indicam a desatenção dos alunos.

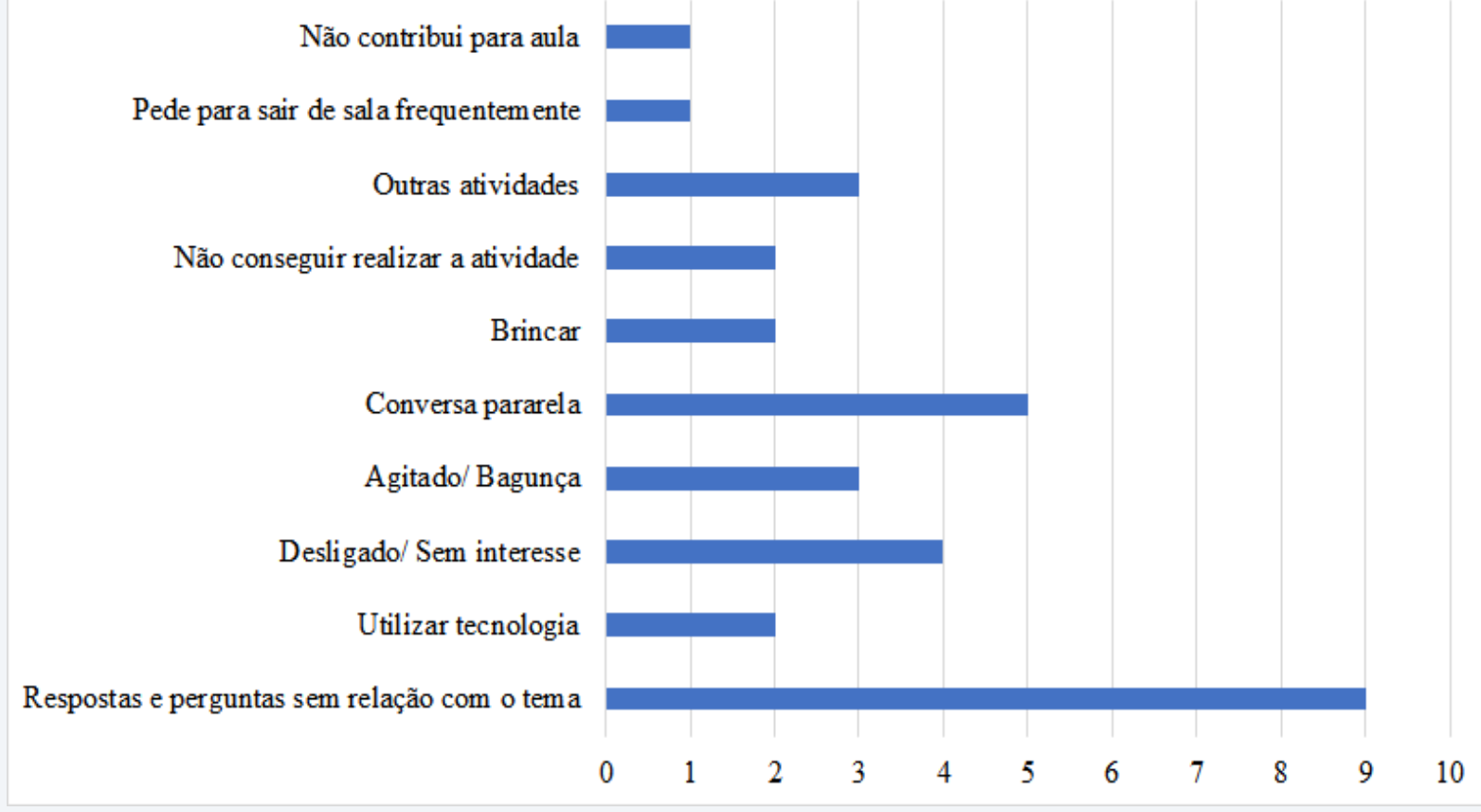

$\mathrm{Na}$ desatenção associada a conversas paralelas sobre outros assuntos, representou uma queixa recorrente dos professores entrevistados, identificadas em transcrições como: "Quando há conversas paralelas; quando é questionado e não sabe responder; quando fazer questionamentos sobre outras coisas que não tem relação com o conteúdo" (Entrevistado 6). Outro comportamento relacionado a desatenção foram as brincadeiras no momento da explicação como destaca a entrevistada 7: "Brincando, olhando para o ar sem um foco, conversando com os colegas, ou fazendo algo que não é o momento propício, são pequenos comportamentos que percebemos que a interação do aluno com a aula não está legal." Outro comportamento destacado foi quanto ao uso do celular para outros assunto durante a explicação da professora: "Quanto o aluno está manuseando o celular durante a aula, com conteúdos alheios aos da explicação da professora (jogos e whatsapp)” (Entrevistado 3). 
Outro comportamento fortemente associado à desatenção pelo professor refere-se as situações em que os alunos são questionados sobre determinado assunto discutido em aula e não sabem responder. Têm-se transcrições com as que seguem que ilustram este comportamento: "Quando ao ser questionado não consegue falar sobre o que está sendo falado" (Entrevistado 2) ou ainda "Quando é feita alguma pergunta e ela não sabe o que está sendo falando ou que responda uma pergunta relacionada ao início da aula" (Entrevistado $5)$.

$\mathrm{Na}$ desatenção tem-se a forte presença de estímulos distratores não relacionados aos processos que ocorrem em sala de aula que contribuem com o processo de aprendizagem. Diante disso, destaca-se que o cérebro não possui a capacidade de apreender todos os estímulos perceptivos que recebe constantemente, para tanto, possui na atenção um mecanismo que realiza esta ação, selecionando as informações que são importantes e dispensando aquelas não relevantes (CONSENZA; GUERRA, 2011; MATLIN, 2003; STERNBERG, 2008). Diante disso, tem-se a atenção seletiva relacionada às opções que fazemos com relação aos estímulos, quais prestamos atenção e quais ignoramos (STERNBERG, 2008)

A partir disso, dialogamos sobre o que os professores fazem para manter a atenção dos alunos durante as aulas. De forma geral, os professores conversam com os seus alunos, diversificam e diferenciam as aulas, estimulam a participação, dinâmicas e propõem brincadeiras, como podemos observar na transcrição da entrevistada 11: "Eu procuro fazer atividades diferenciadas, dinâmicas que interagem com o aluno, buscando a interação dele: ele falar, ele participar, porque no momento em que ele começa a participar, ele começa a prestar atenção" e também da entrevistada 3: "Tento fazer uma aula dinâmica bem explicada com brincadeiras, associando os conteúdos ao cotidiano do aluno”.

Outra estratégia descrita foi o estabelecimento de combinados com o grupo, como ressalta a entrevistada 18 "Estratégias e combinados com eles...[...] Eles têm momentos de prestar atenção em aula e momentos para brincadeiras. Se não prestarem atenção, não são liberados para algumas atividades, tudo é negociado [...].” e além disso o uso de recursos visuais e da ludicidade como ilustram as seguintes falas: "Tento usar todos os recursos disponíveis: visual, auditivo e cinestésico" (Entrevistada 20) e também: "Passa o assunto de um jeito interessante para o aluno, mais lúdico" (Entrevistada 13).

As respostas transcritas analisadas por meio da nuvem de palavras da figura 1 sobre as estratégias utilizadas pelas professoras para manter a atenção, para além as palavras 
relacionadas ao contexto da pergunta, destacam-se a atividade, o chamar, perguntas, dinâmicas diferentes e diversificar.

Figura 1- Nuvem de palavras sobre as estratégias utilizadas pelas professoras para manter a atenção dos alunos.

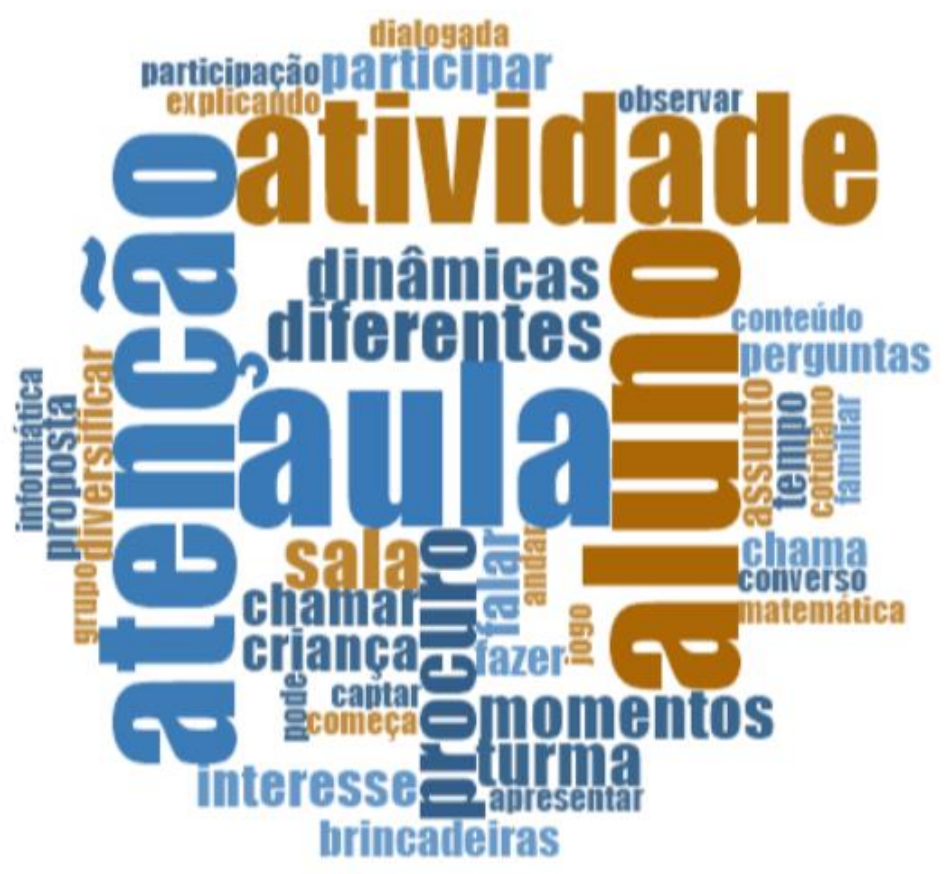

A partir desse contexto, pesquisas como a de Nardin e Sordi (2007) realizada com crianças em sala de aula, apontam que a atenção dos alunos é favorecida em ambientes em que se proporcione uma comunicação dialógica entre os alunos, proporcionando novas interpretações e ressignificações. Com outro olhar, Ribeiro (2015) ao propor o uso de jogos digitais para melhorar a atenção, explora o lúdico e o próprio uso das tecnologias.

$\mathrm{Na}$ busca por compreender a atenção em sala de aula, investigou-se, ainda, as estratégias utilizadas pelos professores quando eles percebem que os alunos não estão atentos em sala de aula. Os resultados revelaram estratégias como chamar a atenção do aluno, principalmente, chamando-os pelo nome, conversar com o aluno individualmente, mudar a atividade ou o método utilizado na aula.

$\mathrm{Na}$ primeira categoria identificada as respostas relacionam-se com chamada de atenção do aluno, inclusive interrompendo a aula para fazer tal chamada, como ilustra algumas falas dos professores: "Geralmente chamo pelo nome do aluno, peço que dê exemplo ou me explique alguma coisa" (Entrevistado 17) ou ainda "Quando vejo que tem alunos que não prestam atenção, dou exemplos e chamo o nome deste aluno para que me ajude a 
demonstrar, pergunto se está entendendo, repito a explicação novamente, eu faço a explicação na atuação da atividade [...]" (Entrevistado 7).

Outra categoria identificada refere-se a estabelecer uma conversa com os alunos de forma mais discreta que aparece de forma cuidadosa como: "Busco conversar individualmente para compreender o que está se passando. Se isso persistir, tento alterar as dinâmicas da aula de modo que o aluno se sinta convidado a interagir e participar" (Entrevistado 12) ou ainda uma conversa num âmbito coletivo: "Converso com eles/elas, explico a importância da disciplina e da matéria e se nada adiantar dou bronca, e se não adiantar encaminho para orientação” (Entrevistado 1).

Além disso, alguns professores relatam mudar de atividade ou método aplicado em sala no momento em que observam a desatenção, trazendo um olhar sensível do professor frente ao aluno, como ilustra a fala: "Mudo a didática dentro de sala de aula, faz a leitura em conjunto. faz um círculo e pergunta o que não entenderam [...]" (Entrevistado 18).

Quando os professores foram instigados a perceber o que mais prende a atenção dos alunos na sala de aula, referente a recursos, atividades e estratégias, tivemos uma variedade de relatos, destacando-se o uso de jogos e brincadeiras e o conteúdo significativo.

Gráfico 3 - Atividades que prendem a atenção do aluno segundo as professoras.

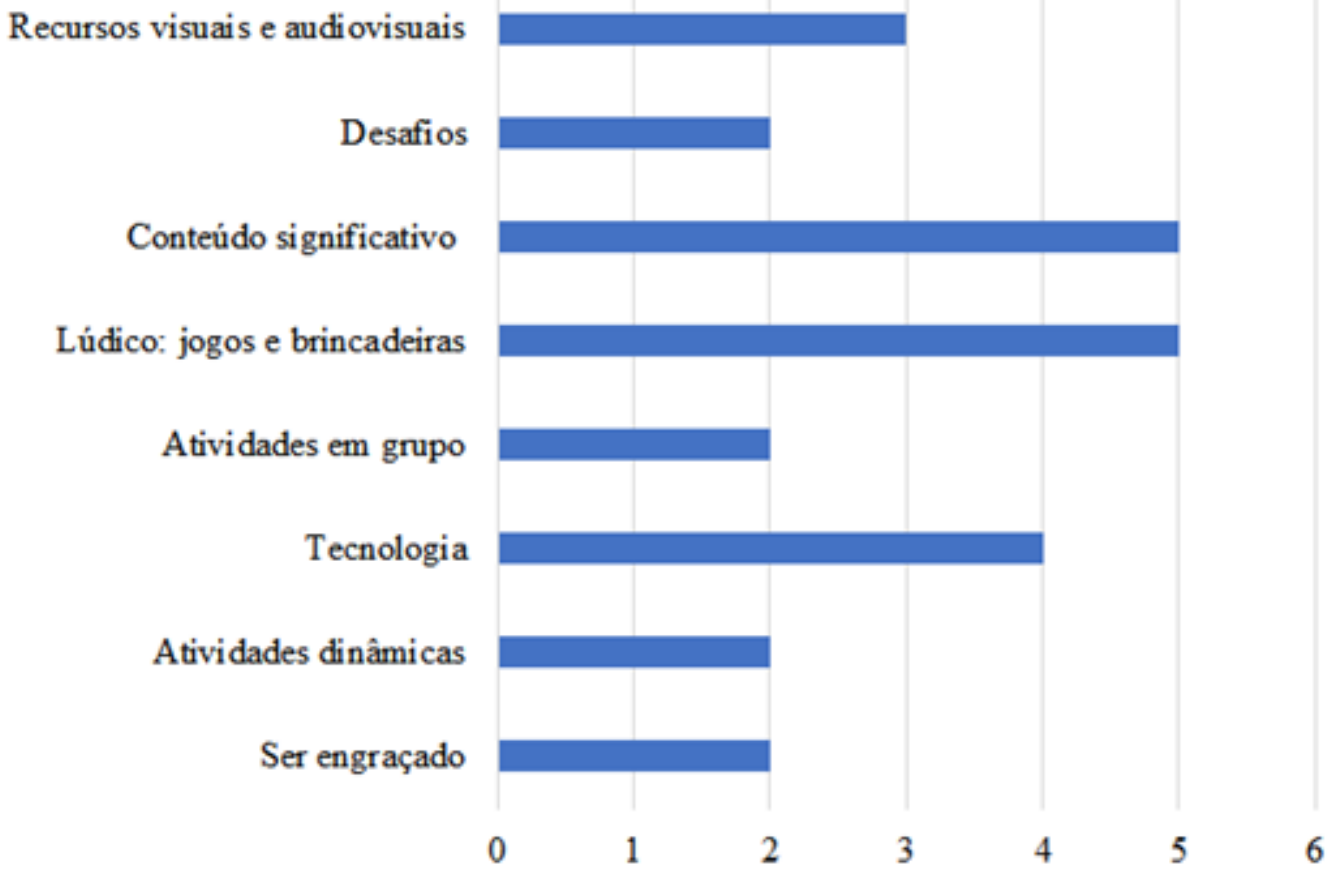


Além disso, os professores destacaram as características da própria aula relacionada ao bom preparo da mesma, boas dinâmicas que suscitam a aprendizagem do aluno bem como a atuação de um professor motivado com a sua prática pedagógica, destacando na fala: " $E u$ acho que um bom preparo da aula, um bom planejamento, utilizando recursos variados, buscando interagir sempre com eles, trazer o conhecimento prévio deles, agregar o conhecimento junto a esse conhecimento prévio que ele tem; aquilo que ele já traz consigo... A realidade dele, a vivência dele. Daquilo que ele sabe, vai ligar um conhecimento novo. Sempre fazer atividades práticas, dinâmicas, diferenciadas. Porque a aula é "muito chata", então se não for assim, "não tem graça" (Entrevistado 11) ou ainda "Bom humor, professora humorada, palavras engraçadas, uso de exemplos que tem a ver com os gostos da faixa etária." (Entrevistada 7).

Diante desse contexto de atenção no processo de ensino e aprendizagem, destacamos a fala da professora que ressalta a atribuição de significado pelos alunos: "Atividades que dão significados para os alunos. Que trabalha com a realidade na qual eles estão inseridos, tentando fazer ganchos com o que a educação pode contribuir com eles. Mas também vai depender das especificidades e subjetividades de cada aluno [...]" (Entrevistada 15).

\section{Considerações finais}

O estudo desenvolvido parte da compreensão de que a atenção é um mecanismo cognitivo essencial para o estabelecimento de aprendizagens, vivências e experiências em todos os âmbitos de nossa vida. Os conceitos descritos sobre essa função intelectiva e os resultados das análises das entrevistas com professores de ensino fundamental, reforçaram a sua relevância no espaço escolar, os aspectos relacionados a observações e as práxis voltadas à sustentação da atenção.

Com base nas análises das transcrições das entrevistas identificou-se que a associação que os professores realizam sob a atenção se direciona aos aspectos do foco, da compreensão do conteúdo, da motivação e da participação. No que diz respeito aos indicadores da atenção e desatenção, ao primeiro termo surgiram às ações: participação e feedback, enquanto na desatenção destacou-se as conversas paralelas, as brincadeiras em momento inadequado, o uso do celular e não responder de modo coerente o que é perguntado.

Sobre as ações que os professores tomam para manter a atenção de seus alunos durante a aula, os professores, de modo geral, expuseram que conversam com os seus alunos; diversificam e diferenciam as aulas; estabelecem combinados com o grupo; mudam de 
atividade ou método aplicado; chamam atenção; conversam de modo mais discreto; usam recursos visuais, lúdicos e tecnológicos. Ao mesmo tempo em que revelam ter a consciência de que é na relevância e na relação com a experiência prévia dos alunos que a atenção terá maiores possibilidades de se sustentar e consequentemente, possibilitar a aprendizagem.

Nesse sentido, a atenção se apresenta como uma atividade mental que tem como base as funções cognitivas, as vivências e as relações psicossociais que os indivíduos estabelecem com o mundo que os cercam. Em torno dos aspectos levantados pela pesquisa, salientamos a importância do olhar sensível do professor frente às ações e comportamentos intelectuais de seus alunos, como meio de respeito a suas especificidades e singularidades, bem como de compreensão de seus mecanismos de ação e apreensão para que práticas de aprendizagens e vivências significativas possam ser oportunizadas.

\section{REFERÊNCIAS}

BARDIN, Laurence. Análise de conteúdo. Lisboa: Edições 70, 2007.

BRUNNER, Reinhard \& ZELTNER, Wolfgang. Dicionário de Psicopedagogia e Psicologia Educacional. $4^{\text {a }}$ edição. Rio de Janeiro: Vozes, 1994.

COSENZA, Ramon; GUERRA, Leonor B. Neurociência e educação: como o cérebro aprende. Porto Alegre: Artmed, 2011.

DIAMOND, Adele. Atividades e programas que melhoram as funções executivas das crianças. In: OLIVEIRA, João Batista Araújo (Org.). Educação Infantil: evidências científicas e melhores práticas. Instituto Alfa e Beto, 2012. p. 141-157.

DIAMOND, Adele. Executive Functions. Annual Review of Psychology [online], v. 64, p.135-168, Jul. 2013.

GUERRA, Leonor Bezerra. O diálogo entre a neurociência e educação: da euforia aos desafios e possibilidades. Revista Interlocução [online], v.4, n.4, p.3-12, Jun. 2011.

HARDIMAN, Mariale, MAGSAMEN, Suzan, MCKHANN, Guy, EILBER, Janet.

Neuroeducation: Learning, Arts, and the Brain. Washington: Dana Press, 2009.

HARVARD, University. Construindo o sistema de "Controle de Tráfego Aéreo" do

cérebro: Como as primeiras experiências moldam o desenvolvimento das funções executivas. Estudo n. 11. Center on the Developing Child, 2011. Disponível em: http://www.developing child.harvard.edu, 2011. Acesso em 7 de junho de 2016.

LADEWIG, Iverson. A importância da atenção na aprendizagem de habilidades motoras.

Revista Paulista de Educação Física, São Paulo, n 3, p. 62- 71, 2000. 
LENT, Robert. Cem bilhões de neurônios: Conceitos fundamentais de neurociência. São Paulo: Editora Atheneu, 2010.

LEZAK, Muriel Deutsch. Neuropsychological Assessment. New York: Oxford University Press, 1995.

LIMA, Elvira Souza. Neurociência e aprendizagem. São Paulo: InterAlia, 2009. MATLIN, Margarete. Psicologia Cognitiva. 5. ed. Rio de Janeiro: LTC, 2003.

MICARONI, Natália Inhauser Rótoli; CRENITTE, Patrícia Abreu Pinheiro; CIASCA, Sylvia Maria. A prática docente frente à desatenção dos alunos no ensino fundamental. Revista CEFAC, Campinas/SP, v. 12, n. 5, p. 756, set-out. 2010.

MOURÃO JUNIOR, Carlos Alberto; MELO, Luciene Bandeira Rodrigues. Integração de três conceitos: função executiva, memória de trabalho e aprendizado. Psicologia: Teoria e Pesquisa, Brasília, v. 27, n. 3, p. 309-314, Jul-Set. 2011.

NARDIN, Maria Helena de; SORDI, Regina Orgler. Um estudo sobre as formas de atenção na sala de aula e suas implicações para a aprendizagem. Psicologia e Sociedade. [online] v.19, n.1, p. 99-106, Jan-Abril. 2007.

RAMOS, Daniela Karine, ROCHA, Natália Lorenzetti da, RODRIGUES, Katia, ROISENBERG, Bruna Berger. O uso de jogos cognitivos no contexto escolar: contribuições às funções executivas. Psicologia Escolar e Educacional [online], v.21, n.2, pp.265-275, Maio-Ago. 2017.

RIBEIRO, Simone Pletz. Contribuições do Jogo Cognitivo Eletrônico ao aprimoramento da Atenção no Contexto Escolar. 2015. 149 f. Dissertação (Mestrado em Educação) Programa de Pós-graduação em Educação, Universidade Federal de Santa Catarina, Florianópolis, 2015.

RUEDA, Maria Rosario, CHECA, Puri, CÓMBITA, Lina. M. Enhanced efficiency of the executive attention network after training in preschool children: Immediate changes and effects after two months. Developmental Cognitive Neuroscience [online], v. 2, p. 192-204, Fev. 2012.

SPENCE, Charles. Attention. In: RAMACHANDRAN, Vilayanur S. Encyclopedia of Human Behavior. ${ }^{a}$ ed. San Diego, CA: Academic Press, 2012, p. 211-217.

STERNBERG, Robert. Psicologia Cognitiva. 4ed. Porto Alegre: Artmed, 2008. 


\section{SOBRE AS AUTORAS:}

\section{Daniela Karine Ramos}

Doutora em Educação pela Universidade Federal de Santa Catarina (UFSC). Atualmente é professora adjunta no Departamento de Metodologia de Ensino e do Programa de PósGraduação em Educação do Centro de Ciências da Educação da UFSC e desenvolve pesquisas relacionadas a educação a distância, ao uso de tecnologias na educação, aos jogos eletrônicos e aos aspectos didáticos do processo de ensino e aprendizagem. E-mail: dadaniela@gmail.com

\section{ORCID http://orcid.org/0000-0001-9833-310X}

\section{Bruna Santana Anastácio}

Doutoranda em Educação pela Universidade Federal de Santa Catarina (UFSC). Membro do Grupo de Pesquisa Edumídias. E-mail: brunaanastacio@ hotmail.com

\section{ORCiD http://orcid.org/0000-0002-5631-0070}

\section{Camila Meurer Jacob}

Mestranda pela Universidade Federal de Santa Catarina (UFSC). Membro do grupo de pesquisa Edumídia. Atualmente é Pedagoga do Centro de Tecnologia Assistiva (CETEP) da Fundação Catarinense de Educação Especial (FCEE). E-mail: camilameurerjacob@gmail.com

ORCID http://orcid.org/0000-0003-2430-2911

\section{Mariana Carreira Oliveira}

Mestranda em Educação pela Universidade Federal de Santa Catarina (UFSC). Pesquisadora de jogos, língua estrangeira, ciência cognitiva e processo de ensino-aprendizagem. Atua como professora de Educação Infantil em uma escola bilíngue. Membro do grupo de pesquisa Edumídia. E-mail: mari_c.o@outlook.com

$$
\text { http://orcid.org/0000-0002-5888-6655 }
$$

